\title{
Substance use Among Street Children in Tehran, Iran
}

\author{
Masoumeh Dejman ${ }^{1,}$, Meroe Vameqhi' ${ }^{2,}$, Fatemeh Dejman ${ }^{3}$, Payam Roshanfekr ${ }^{2}$, Hassan Rafiey ${ }^{2}$, Ameneh Setareh \\ Forouzan $^{2}$, Majid Rezazadeh $^{4}$, Parisa Fazeli' ${ }^{5}$, Shervin Assari ${ }^{6,7}$ \\ 1. Mental Health Department, Bloomberg School of Public Health, Baltimore, Johns Hopkins University, MD, USA \\ 2. Social Welfare Management Research Center \& Social Determinants of Health Research Center, University of Social Welfare and \\ Rehabilitation Sciences, Tehran, Iran \\ 3. Clinical Psychology, Tehran University, Tehran, Iran \\ 4. Preventing Development Center, State Welfare Organization of Iran, Tehran, Iran \\ 5. Prevention Development Committee, State Welfare Organization of Iran, Tehran, Iran \\ 6. Center for Research on Ethnicity, Culture and Health, University of Michigan School of Public Health, Ann Arbor, MI, USA \\ 7. Department of Psychiatry, University of Michigan, Ann Arbor, MI, USA
}

*Corresponding Author: Meroe Vameqhi, MD, Social Welfare Management Research Center \& Social Determinants of Health Research Center, University of Social Health and Rehabilitation Sciences, Tehran, Iran

Email: m_vameghi@yahoo.com

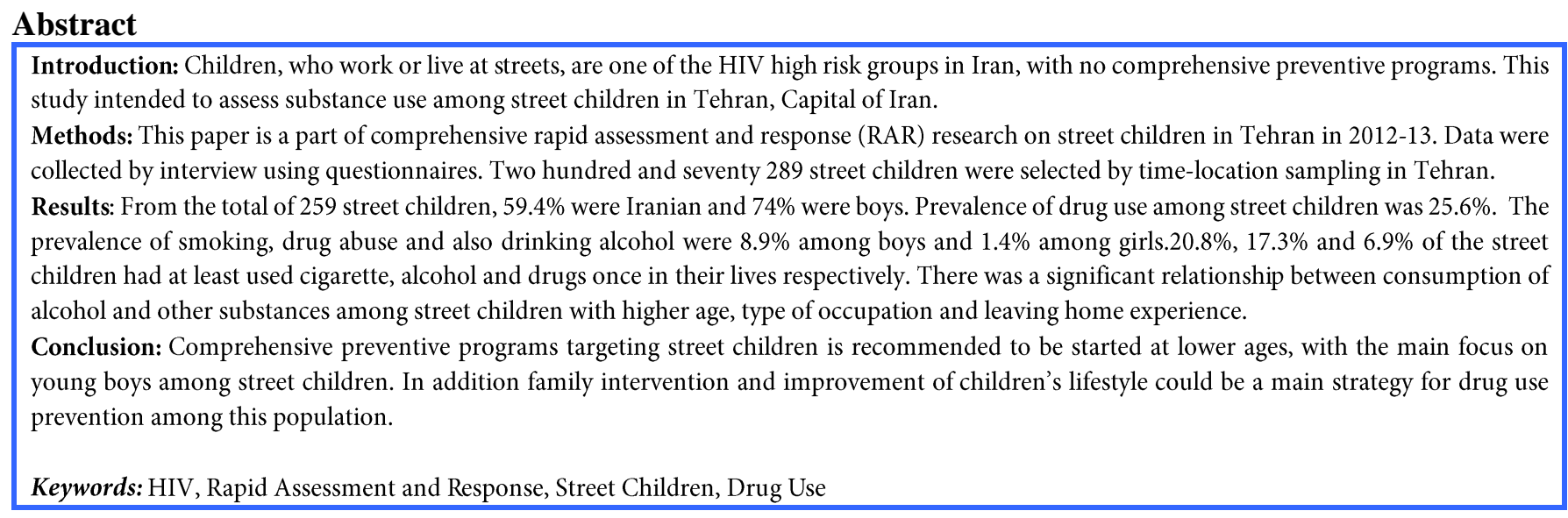

Article History: Received: 2 Jul 2014; Revised: 25 Jul 2014; Accepted: 1 Aug 2014

Cite this article as: Dejman M, Vameqhi M, Dejman F, Roshanfekr P, Rafiey H, Setareh Forouzan A, Rezazadeh M, Fazeli P, Assari S. Substance use among street children in Tehran, Iran. Int J Travel Med Glob Health. 2015;3(1):23-7.

\section{Introduction}

Despite the scientific developments in regards to recognizing and responding to the epidemic of AIDS, and also the different patterns in the vulnerable groups, nowadays we are facing the prevalence of HIV in the vulnerable groups of the society [1].

The unsafe injecting and high risk sexual behaviors are known as important causes of disease transmission all over the world especially in Asia, Eastern Europe and America. In some regions, sexual relationships have a more important role, for instance in India in 2005, one in five believed that HIV cases were caused by unsafe sexual relationships [2]. According to the last report of the National AIDS Committee Secretariat in Iran, the prevalence of HIV/ AIDS in the high risk groups of the society were as follows: $15 \%$ injecting drug users, $6.6 \%$ injecting drug users with unsafe sexual relationship, and $4.5 \%$ female sex workers [3].

One of the high risk groups of the world society who have the risk to encounter HIV infection are the street children [4]. The risk of HIV infection among street children may be es- pecially high due to marginalized social and economic situations, as well as substance abuse and other high risk behaviors [5].

In Mohraz and Shoqli's [6] study in 2010 on the street children in Tehran, results showed that $40.1 \%$ of the children drink alcohol and $19.6 \%$ of them were addicted to drugs. In the same study, the HIV prevalence among the street children of Tehran was estimated $4.6 \%$. In children who used drugs this amount increased to $9 \%$. In a study conducted in Egypt and Nigeria, drug abuse among street children was reported $62 \%$, which increased the risk of other diseases [7]. According to the last National report of AIDS, increase in the population of street children, facing the risks of the HIV and sexual transmitted diseases are within the main threats in regards to the condition of HIV in Iran. The lack of precise information in regards to the high risk behaviors of street children, has caused the decision makers not be able to design scientific programs in this regard. Rapid assessments of street children might help to collect deep information about this high risk group to plan appropriate intervention. This 
paper is a part of a broad study in regards to rapid assessments of high risk behavior of street children. The aim of this study was to describe the condition of drug abuse in street children.

\section{Methods}

This paper is a part of a comprehensive Rapid Assessment and Response (RAR) research on street children in 20122013. The population of the study was street children recruited from Tehran, capital of Iran. In this study, street children were considered the Iranian and non-Iranian children who spent long hours of a day in the streets of Tehran (living and working). The sample size of the study was 289 street children who were selected by time-location sampling in Tehran. As for a qualitative study being aware of the location of which these children work is essential, at first the information about their location was gathered. For considering the variety of the locations in regards to the economic-social characteristics of the different areas of Tehran, the listed locations were divided into three zones based on the three development zoning areas of Tehran.

According to this zoning, the districts9, 10, 12, 16, 17, 18 and 19 were considered as low developed zones. Areas 7, 8, 11, $13,14,15,20$ and 21 were considered as middle developed zones and lastly the districts1, 2, 3, 4, 5, 6 and 22 were highly developed zones. From the highly developed zone, ten areas, from the middle developed zone nine areas and from the low developed zone nine areas were randomly chosen.

At the same time a list containing 28 alternative places was prepared just in case the other districts were empty of street children.

Data were gathered by using the interview technique and structured questionnaire. The interviewers were a team of experienced academics, and had at least master degree with history of doing research. Before sending these experts out for gathering data, a meeting was held to exactly inform them about all the questions of the questionnaire. The questions were asked from the street children who had accepted to take part in the survey. Two interviewers conducted the interviews in each area. One woman did the interview and a man watched the location.

In order to be aware of the exact time and place of which the street children were present, and an estimation of the minimum and maximum number of the street children in each location (based on the checklist), information was gathered from the local key informant in each area. These people were neighbors, taxi or bus drivers, the parks' and shopping centers' guards, the metro staff and the police. After this stage, the interviewers were sent to the defined locations from 8:00 am until 8:00 pm.

The quantitative section of the questionnaire was gathered by reviewing the other questionnaires available in this field. At the end, after several meetings, the final questionnaire was approved by the research team. This questionnaire consisted of 59 questions that were divided into 6 sections. These sections were as follows: demographic, family, the type of job, substance abuse, sexual behavior and interventions.

The questionnaire contained 59 items that consisted of $6 \mathrm{sec}-$ tions. These sections included the demographic questions, family, and jobs of the children, substance abuse and sexual behaviors. This paper presents the findings of substance use behavior of street children. Data were analyzed descriptively and analytically using the SPSS software version 21 .

With respect to the legal obligations of the welfare organization of the country, as the only trustee of the street children (In 1378, the Supreme Administration Council approved that, from this date the Welfare Organization is the only trustee of the street children under the age of 18.), the AIDS prevention and control committee of the welfare organization gave us the permission to hand out questionnaires to the street children. This research gained an approval code of USWR.REC.1393.3 from the ethics committee of the University of Social Welfare and Rehabilitation.

\section{Results}

From the total of 259 street children, 59.4\% were Iranian and $36.3 \%$ were from Pakistan and Afghanistan. $74 \%$ of street children were boys. As to their age, 5.8\% were under ten, $45.3 \%$ were between the ages ten to fifteen and $48.9 \%$ were between the ages of fifteen to eighteen. $54.9 \%$ of the street children lived in low developed zones, especially district 12 (38\%). The highest frequency of the region of which the street children worked belonged to the district 2 (45\%), district $12(18 \%)$ and district 1 (11.1\%).

\subsection{Prevalence of Drug Use in Street Children}

From the total of 289 children, considering fourteen of them who denied answering this question, $25.6 \%$ (74 children) had an experience of smoking, drug use and also drinking alcohol. The prevalence of smoking, drug use and also drinking alcohol were $8.9 \%$ among boys and $1.4 \%$ among girls. $56.8 \%$ of the children started using these products before the age of fourteen. $1.4 \%$ of them were between ten and fourteen and $11.8 \%$ of them were between fifteen and eighteen (table 1). No scientific association found between Iranian and nonIranian, single and married and also educating and non-educating.

Among the children with experience in smoking or/ drug abuse and drinking alcohol, the most prevalent substances used were cigarettes (71.4\%), then alcohol (65.3\%) and drugs (48.4\%) had lower rank. In $27 \%$ of them, first used substance was an illicit drug.

$20.8 \%, 17.3 \%$ and $6.9 \%$ of the street children had at least used cigarette, alcohol and drugs once in their lives respectively. Among the 47 children who had at least used substances once in their lives and had also answered to this question, nineteen children (57.6\%) had daily use of alcohol and fifteen children (71.4\%) had daily use of Tobacco. Daily use of Cigarettes was about an average of ten. 
Table 1. Frequency of the first substance and substance used in the last six months in Tehran's street children in 2013

\begin{tabular}{llcc}
\hline & Title & The First Substance Used (N=74) & Substance Used in the Last Six Months \\
\hline 1 & Cigarette & $47(63.5 \%)$ & $26(53.1 \%)$ \\
2 & Hookah & $13(17.6 \%)$ & $9(18.4 \%)$ \\
3 & High Concentrated Ethanol & $11(14.9 \%)$ & $7(14.3 \%)$ \\
4 & Other Alcoholic beverages & $39(52.7 \%)$ & $25(51 \%)$ \\
5 & Ecstasy & $6(8.1 \%)$ & $5(10.2 \%)$ \\
6 & Smoking and Eating Opium & $6(8.1 \%)$ & $7(14.2 \%)$ \\
7 & Injection or Non-injection Use of Heroin and Crack & $2(2.7 \%)$ & $1(2.0 \%)$ \\
8 & Other Substances (Hashish, Pan, Methadone, etc) & $6(8.1 \%)$ & $7(14.3 \%)$ \\
\hline
\end{tabular}

It can be said that the most prevalent substances used among the street children six months before our study were cigarettes $12.1 \%$ (35 children), alcohol $11.1 \%$ (32 children) and drug use $6.9 \%$ (20 children) respectively (Table 1 ). The most common places of where street children used substances were their own homes (41.6\%), their friends' homes (22.9\%) and the streets $(20.8 \%)$ respectively.

\subsection{Factors Associated with Substance Use}

Significant association was found between use of alcohol and age, type of work and the period of which the children had left home (Table 2). The highest age range of alcohol consumption in Iranian street children was from 15 to 18 for those of which had left home and were occupied in unconventional jobs such as drug dealing, robbery, and sex work. Alcohol consumption in the children who had an experience in substance use (50\%) or smoking cigarettes $(58.1 \%)$ was significantly higher than those without substance abuse (7.1\%) and cigarette consumption (4.3\%).

In this study results show that substance use increases significantly as age increases. Also, in the children who had left home, substance use was much higher (18.8\%). Substance use in between the children with unstandardized jobs (Unstandardized jobs include buying and selling drugs, pickpocketing, prostitution and tramping) (66.7\%) was much higher in compared to the street children with standard (Standard jobs include colportage, freight, footwork and musical performances) jobs (4.7\%) or half standardized (Halfstandardized jobs include beggary and gathering rubbish) jobs (10.2\%) $\mathrm{P} \prec 0.001$ (Table 3 ). Also, it can be said that there is a significant relationship in going under hard jobs in between Iranian children (0\%) and non-Iranian children (28.6\%) $(\mathrm{P}=0.019)$.

\subsection{Reasons of Drug and Alcohol Use in Street Children}

The most frequent reasons that street children start using drugs were curiosity (56.6\%), enjoying time and pleasure $(39.6 \%)$ and recreation (35.8\%). Tolerating hard work had as a reason for substance use had the least frequency among non-Iranian street children $(28.6 \%)$ and no Iranian street children reported it as a reason for drugs use.

The most prevalent problems in regards to substance use in 33 children (among the 73 street children with substance abuse) who had answered this item, were $51.5 \%$ (17 children) due to quarrels and battles, $12.1 \%$ (4 children) due to overdosing and being arrested. Sexual harassment 6\% (2 children) and accidents ( 1 child) had the lowest frequency.
Table 2. Relationship between the frequency of alcohol consumption and the demographic characteristics of the street children of Tehran in 2013

\begin{tabular}{|c|c|c|c|}
\hline & & $\begin{array}{c}\text { Frequency of Alcohol } \\
\text { Consumption in } \\
\text { Street Children }\end{array}$ & $\mathbf{P}$ \\
\hline \multirow{2}{*}{ Nationality ${ }^{*}$} & Iranian & $13.5 \%(23)$ & \multirow{2}{*}{0.003} \\
\hline & Non-Iranian & $2.8 \%(3)$ & \\
\hline \multirow{2}{*}{$\operatorname{Age}^{*}$} & $10-14$ & $2.1 \%(3)$ & \multirow{2}{*}{0.001} \\
\hline & $15-18$ & $17.6 \%(24)$ & \\
\hline \multirow{2}{*}{ Leaving home ${ }^{*}$} & Yes & $18.8 \%(15)$ & \multirow{2}{*}{0.004} \\
\hline & No & $6.3 \%(11)$ & \\
\hline \multirow{3}{*}{ Type of work ${ }^{*}$} & Standard & $8.5 \%(20)$ & \multirow{3}{*}{0.001} \\
\hline & $\begin{array}{l}\text { Half-stand- } \\
\text { ardized }\end{array}$ & $10.2 \%(5)$ & \\
\hline & $\begin{array}{l}\text { Unstand- } \\
\text { ardized }\end{array}$ & $66.7 \%(4)$ & \\
\hline
\end{tabular}

${ }^{\star}: \mathrm{P}<0.001$

Table 3. Relationship between the frequency of substance abuse and the demographic characteristics of the Tehran street children in 2013

\begin{tabular}{|c|c|c|}
\hline \multicolumn{2}{|c|}{ Demographic Characteristics } & \multirow{2}{*}{$\begin{array}{c}\text { Frequency of Sub- } \\
\text { stance Abuse in } \\
\text { Street Children } \\
1.4 \% \text { (1) }\end{array}$} \\
\hline \multirow{2}{*}{ Gender* } & Girl & \\
\hline & Boy & $8.9 \%(19)$ \\
\hline \multirow{2}{*}{ Age $^{*}$} & $10-14$ & $1.4 \%(2)$ \\
\hline & $15-18$ & $11.8 \%(16)$ \\
\hline \multirow{3}{*}{ Type of job* } & Standard & $4.7 \%(11)$ \\
\hline & Half-standardized & $10.2 \%(5)$ \\
\hline & Unstandardized & $66.7 \%(4)$ \\
\hline \multirow{2}{*}{ Leaving home ${ }^{*}$} & Yes & $16.3 \%(13)$ \\
\hline & No & $3.4 \%(6)$ \\
\hline
\end{tabular}

${ }^{*}: \mathrm{P}<0.001$

\section{Discussion}

Results showed that $17.3 \%$ of the street children had at least once used alcohol and $6.9 \%$ had at least once used illicit drugs throughout their life. There was no significant difference in between boys and girls in consumption alcohol and substance abuse. The age in which street children started substance use is very low. Actually $56 \%$ of them started substance use before the age of fourteen. Yet, substance use in older street children (15 to 18) was significantly higher. There was also a significant association between alcohol, drug and cigarette use. As results reveal, about 7\% of the street children have used drugs (with or without alcohol) at least once. According to Vameghi et al.'s study, [8] this prevalence differs in the different parts of the country. The least amount of frequency of substance use (18\%) belonged to the centers affiliated to the well-being organization of the country and the highest amount (70\%) belongs to the Houra center in Roudehen city and also the Tehran's street children. 
Table 4. Relationship between gender and over dose of substance abuse street children in Tehran in 2013

\begin{tabular}{cccc}
\hline Over Dose of Substance Abuse & Boy & \multicolumn{1}{c}{ Girl } & Frequency n=6 (\%) \\
\hline Yes & Frequency n=27 (\%) & $3(50 \%)$ & Q2=9.87 \\
No & $1(3.7 \%)$ & $26(96.3 \%)$ & $3(50 \%)$ \\
\hline
\end{tabular}

In another study which was conducted on 1,000 Tehran street children, results showed that $59.8 \%$ (598) of the studied children had experiences in using cigarettes and $40.1 \%$ (401) of the studied children had experiences in drinking alcohol [6]. In a study conducted in Pakistan, results reveal that 3500 to 5000 street children live in Lahour. Among them, $15 \%$ had an experience in the past and $67 \%$ of them had and experience in the previous month of the study in using drugs. This difference may be due to the specific studied society.

It can be said that an association existed between smoking, drinking alcohol and substance abuse. Shoghi and Mohraz's study also reveal a link between smoking, drinking alcohol and substance abuse [6]. The relationship between smoking, drinking alcohol and substance abuse can be analyzed by the Gateway Drug Theory. According to this theory, using less dangerous drugs can lead to using more dangerous drugs in the future [9].

Considering that the rate of substance abuse and drinking alcohol in street children is much higher in compared to the general population, also considering that the higher these rates get, the more likely for the street children to get addicted, it can be concluded that street children are a high risk group. This means the organizations in charge of these children should schedule preventing, treatment and harm reduction programs.

In the present study, smoking and drinking alcohol in Iranian street children is much higher compared to Afghani children, but there isn't a significant difference in substance abuse in the two groups. In Shoghi and Mohraz's study [6], there was a significant difference in substance abuse in between Iranian and Afghani Street children. In street children who had left home, substance abuse and alcohol consumption was significantly higher. Results showed that leaving home does not improve the children's conditions. In other words, it even leads them to violence, harassment and even substance abuse. This means planning for reducing the rates of home leaving can be a main strategy for decreasing substance abuse.

Results also show that the age in which street children start using drugs is quite low. About $56 \%$ of the street children start substance abuse before the age of 14 . Although it is seen that the rates of smoking, drinking and substance abuse in older street children (15 to 18 ) is much higher. It is said that these rates are also seen in school children. In a study which was conducted on 1,785 school children in Tabriz, 226 (12.6\%) of the students reported drinking at least once in their lives and $36(2 \%)$ had reported at least once of drug abuse [10]. This means drug abuse prevention programs for street teenagers should begin in earlier ages, even before 14 .
The most prevalent problems related to drug abuse of street children in this study were fights and quarrels (51.5\%) followed by over consumption of drugs and getting arrested (12.1\%).Current literature is comparable with the literature on problems that homeless and runaway individuals are experiencing [11-16].

\section{Conclusion}

As a significant association exists between drug abuse, gender, age, leaving home, smoking, drinking alcohol and lighter drugs, it is recommended that drug abuse prevention programs for street teenagers should begin in earlier ages, even before 14 especially for boys. It was seen that substance abuse was prevalent in street children families. Also, in order to make attempts for improving the life conditions of street children, drug abuse prevention programs are main strategies for decreasing drug abuse.

\section{Acknowledgments}

The authors would like to thank University of Social Welfare and Rehabilitation Sciences for the cooperation with the team for interviewing the street children and gathering data.

\section{Authors' Contribution}

The authors' contributions to this study are as follows: Conception and design of the study: MD, MV, ASF, HR, PR Supervision: MV. MD, MR, PF, SA

Data gathering and interview: MD, MV, ASF, HR, PR Analysis: MD, MV, PR

Interpretation of data and drafting: $\mathrm{MD}, \mathrm{MV}, \mathrm{FD}, \mathrm{SA}$

Critical revision for intellectual content: MD, MV, FD, SA

\section{Funding/Support}

This study was funded by National Wellbeing Organization of Iran.

\section{Financial Discloser}

There is no conflict of interest for this study.

\section{References}

1. health mo. Aids issue importance 2013. Available from: http://aids.behdasht.gov.ir/.

2. Staff JUNPoHA, Organization WH, Staff WHO. AIDS epidemic update, December 2006: World Health Organization; 2006.

3. HIV/AIDS JUNPo. Global report: UNAIDS report on the global AIDS epidemic 2013. WHO Library Cataloguing-in-Publication Data. UNAIDS/JC2502/1/E.(http://www. unaids. org/en/media/unaids/contentassets/documents/epidemiology/2013/g r2013/UNAI DS GlobaLReport_2013_en. pdf).

4. Malcolm A, Aggleton P. Rapid assessment and response Adaptation guide for work with especially vulnerable young people. Institute of Education, University of London. 2004.

5. Karmacharya D, Yu D, Dixit S, Rajbhandari R, Subedi B, Shrestha $\mathrm{S}$, et al. A study of the prevalence and risk factors leading to HIV 
infection among a sample of street children and youth of Kathmandu. AIDS Res Therapy. 2012;9(1):25.

6. Shoghli A. Mohrez M. The HIV/AIDS Bio-Behavioral Surveilance Survey of Street children in Tehran. Centers for Disease Control and Prevention (CDC): Ministry of health and medical education, Tehran, Iran, 2010.

7. Sherman SS, Plitt S, ul Hassan S, Cheng Y, Zafar ST. Drug use, street survival, and risk behaviors among street children in Lahore, Pakistan. J Urban Health: Bulletin of the New York Academy of Medicine. 2005;82(3 Suppl 4):iv113-24.

8. Vameghi M, Rafiey H, Sajjadi H, Rashidian A. Disadvantages of being a street child in Iran: a systematic review. Int $\mathrm{J}$ Adolescence Youth. 2013 (ahead-of-print):1-15.

9. Vanyukov MM, Tarter RE, Kirillova GP, Kirisci L, Reynolds MD, Kreek MJ, et al. Common liability to addiction and "gateway hypothesis": theoretical, empirical and evolutionary perspective. Drug Alcohol Dependence. 2012;123 Suppl 1:S3-17.

10. Mohammad Poorasl A, Vahidi R, Fakhari A, Rostami F, Dastghiri S. Substance abuse in Iranian high school students. Addictive behaviors. 2007;32(3):622-7.
11. Kipke MD, Montgomery SB, Simon TR, Iverson EF. "Substance abuse" disorders among runaway and homeless youth. Subst Use Misuse. 1997;32(7-8):969-86.

12. Slesnick N, Prestopnik J. Dual and multiple diagnosis among substance using runaway youth. Am J Drug Alcohol Abuse. 2005;31(1):179-201.

13. Van Leeuwen JM, Hopfer C, Hooks S, White R, Petersen J, Pirkopf J. A snapshot of substance abuse among homeless and runaway youth in Denver, Colorado. J Community Health. 2004;29(3):217-29.

14. Greene JM, Ennett ST, Ringwalt CL. Substance use among runaway and homeless youth in three national samples. Am J Public Health. 1997;87(2):229-35.

15. Bousman CA, Blumberg EJ, Shillington AM, Hovell MF, Ji M, Lehman S, Clapp J. Predictors of substance use among homeless youth in San Diego. Addict Behav. 2005;30(6):1100-10.

16. Slesnick N, Bartle-Haring S, Erdem G, Budde H, Letcher A, Bantchevska D, Patton R. Troubled parents, motivated adolescents: predicting motivation to change substance use among runaways. Addict Behav. 2009;34(8):675-84. 